\title{
EXPERIMENTAL STUDY OF THE INFLUENCE OF ADHESIVE PROPERTIES AND BOND LENGTH ON THE BOND BEHAVIOUR OF NSM FRP BARS IN CONCRETE
}

\author{
Lluís TORRES ${ }^{\mathrm{a}}$, Ibrahim Attia SHARAKY ${ }^{\mathrm{a}}$, ${ }^{\mathrm{b}}$, Cristina BARRIS ${ }^{\mathrm{a}}$, Marta BAENA ${ }^{\mathrm{a}}$ \\ ${ }^{a}$ AMADE, Polytechnic School, University of Girona, Campus Montilivi s/n, 17071 Girona, Spain \\ ${ }^{b}$ Materials Engineering Department, Faculty of Engineering, Zagazig University, B.O. Box 44519, \\ Zagazig, Sharkia, Egypt
}

Received 04 Jun 2013; accepted 25 Sep 2013

\begin{abstract}
The near-surface mounted (NSM) fibre reinforced polymer (FRP) technique is a relatively recent system for strengthening concrete structures. Bond is a key factor in its behaviour, and is affected by many factors whose influence can only be tested through experimental studies. In this study, the modified pull-out test was used to study the effect of epoxy properties and bond length on the behaviour of NSM FRP bars. Three epoxy types, two FRP materials (carbon and glass) and four bond lengths $\left(6 d_{b}, 12 d_{b}, 24 d_{b}\right.$ and $\left.30 d_{b}\right)$ are used. The load capacity, slips at the loaded end and free end and average bond stress are all analysed. The test results indicate that the role of epoxy properties appear to be a key factor in bond performance in the NSM FRP strengthening technique, and that their effect varies depending on bond length and FRP properties.
\end{abstract}

Keywords: bond behaviour, near-surface mounted (NSM), reinforced concrete, fibre reinforced polymer (FRP), adhesive, failure load.

\section{Introduction}

The strengthening of concrete, masonry and wood members has become an important issue in view of the urgent need to increase the capacity of many old buildings. The most common techniques for strengthening reinforced concrete (RC) structures using fibre reinforced polymer (FRP) systems are externally bonded reinforcement (EBR) and nearsurface mounted (NSM) reinforcement (ACI 440.2R-08 2008; Bulavs et al. 2005, Hajsadeghi et al. 2011). The NSM FRP technique is the more recent and consequently not as much is known about it as is the case with EBR FRP methodology. Compared to EBR, NSM reinforcement has advantages in terms of better protection of FRP, aesthetics, and bond behaviour (De Lorenzis, Teng 2007). From the mechanical point of view, the NSM technique is more effective in flexural and shear strengthening (Barros et al. 2007), the bond between NSM FRP and concrete being the main factor affecting the efficiency of the methodology. Several studies have investigated bond behaviour of NSM reinforcement when the technique is used, and the effect of the main factors involved.

De Lorenzis et al. (2002) performed an experimental study of NSM bond behaviour, using a modified pullout test, to investigate the effect of the type of FRP rod (material and surface pattern), groove-filling material, bond length and groove size on the bond behaviour of NSM bars in concrete. The results showed that for NSM rods bonded with epoxy paste, as the groove size or bond length increased, so did the load capacity. In specimens with cement mortar, splitting of the cover was more frequent than in specimens with epoxy, due to the lower tensile strength of the material. The mode of failure of specimens with ribbed glass fibre reinforced polymer (GFRP) rods ranged from splitting of the epoxy cover, accompanied by cracking of the concrete surrounding the groove, to failure at the epoxy-concrete interface, depending on the groove depth. Soliman et al. (2011) presented an experimental study of the bond behaviour of NSM FRP bars in which concrete tension failure appeared as the main failure mode for most of the tested specimens; groove size and environmental conditions had only a small effect on the failure load.

Galati and De Lorenzis (2009) studied experimentally the effect of construction details and other factors on NSM bond behaviour. The groove dimensions, properties of the bonding materials and type of FRP bars showed a great effect either on the load capacity or on the mode of failure. Sharaky et al. (2013a, 2013b) used the modified pull-out test (De Lorenzis et al. 2002; Soliman et al. 2011) to study the effect of construction de-

Corresponding author: Lluís Torres

E-mail: lluis.torres@udg.edu 
tails, characteristics of FRP bars, adhesive properties, concrete strength and bond length on the bond behaviour of NSM bars. The main failure modes were bar-epoxy interface failure in specimens with NSM carbon fibre reinforced polymer (CFRP) bars, while epoxy splitting and bar damage in specimens with NSM GFRP bars. As the bar diameter, strength and elasticity modulus of adhesive and bond length increased, so did the failure load. Construction details and concrete properties had slight effect on failure load due to bar pull-out or epoxy splitting.

Novidis et al. (2007) studied the bond behaviour of NSM bars. The test results indicated that increasing the groove size resulted in an increase in the average bond strength for failure controlled by the interface between bar and epoxy paste. In addition, increasing the bond length for a given groove size increased the load capacity of the joint. A single shear test was performed to study the bond performance of EBR and NSM FRP systems by Bilotta et al. (2011). The results showed that the ratios of tensile stresses of NSM reinforcement at failure load to the strength of FRP reinforcement was higher than those attained by EBR systems.

Sena-Cruz et al. (2012) studied bond behaviour between glulam and GFRP rods, applied according to the NSM strengthening technique. Observed failure modes included glulam shear failure, interfacial failure (glulam-adhesive and FRP-adhesive) and adhesive splitting. Maximum pull-out force, and the loaded and free ends slips, increased with bond length, while bond strength decreased. A rougher external surface of the rod, and a deeper installation of the GFRP into the groove, made the bond perform better.

The use of NSM technique for strengthening RC beams has also been studied elsewhere (Hassan, Rizkalla 2003, 2004; El-Hacha, Rizkalla 2004; Barros, Fortes 2005; Al Mahmoud et al. 2012, 2009, 2010; Dias, Barros 2010; Costa, Barros 2010; Soliman et al. 2010; Barros et al. 2011). It has been reported that concrete strength has no effect on the load carrying capacity of the strengthened beam when a NSM system failure occurs (Hassan, Rizkalla 2003, 2004; Al Mahmoud et al. 2012). On the other hand, as the tensile strength of epoxy paste and groove dimensions increased the failure load also increased (Hassan, Rizkalla 2004). Due to the high number of factors affecting NSM bond behaviour, more experimental studies are needed for the effect of these factors to be understood, and formulations to help in the design of this system to be obtained.

This paper examines the effect of epoxy properties on the behaviour of NSM bars. A series of experimental tests by means of the modified pull-out test previously indicated (De Lorenzis et al. 2002; Soliman et al. 2011; Sharaky et al. 2013a, 2013b) were carried out. Groove dimensions and concrete type were kept constant. Three epoxy types, two FRP materials (CFRP and GFRP) and bar surfaces and four bond lengths were used. The load capacity, mode of failure and average bond stress-slip are analysed, and results for the different variables are compared and discussed.

\section{Experimental program}

\subsection{Test specimens}

In the experimental program thirty eight specimens having configuration similar to that reported in (Sharaky et al. 2013a, 2013b) were tested. The specimens consisted of C shaped concrete block having outside dimensions of $350 \times 350 \mathrm{~mm}$ and inside dimensions of $170 \times 180 \mathrm{~mm}$ (Fig. 1). Two specimens' heights were used (300 and $350 \mathrm{~mm}$ ). The grooves were shaped by creating two saw cuts and using a hammer to manually remove the remaining concrete in-between the cuts. After cleaning the groove with compressed air and half-filling it with the epoxy resin, the bar was introduced and additional resin was subsequently added to fill the groove till levelling it with the surrounding concrete surface.

\subsection{Characteristics of materials}

The average compressive strength of concrete was $23 \mathrm{MPa}$ while the tensile strength was $2.3 \mathrm{MPa}$, based on the experimental tests performed on standard cylinders $(150 \times 300 \mathrm{~mm})$. Two types of FRP bars, carbon (MBrace, BASF) and glass (ComBAR, SCHOK), were used. The properties of the FRP bars obtained from the experimen-
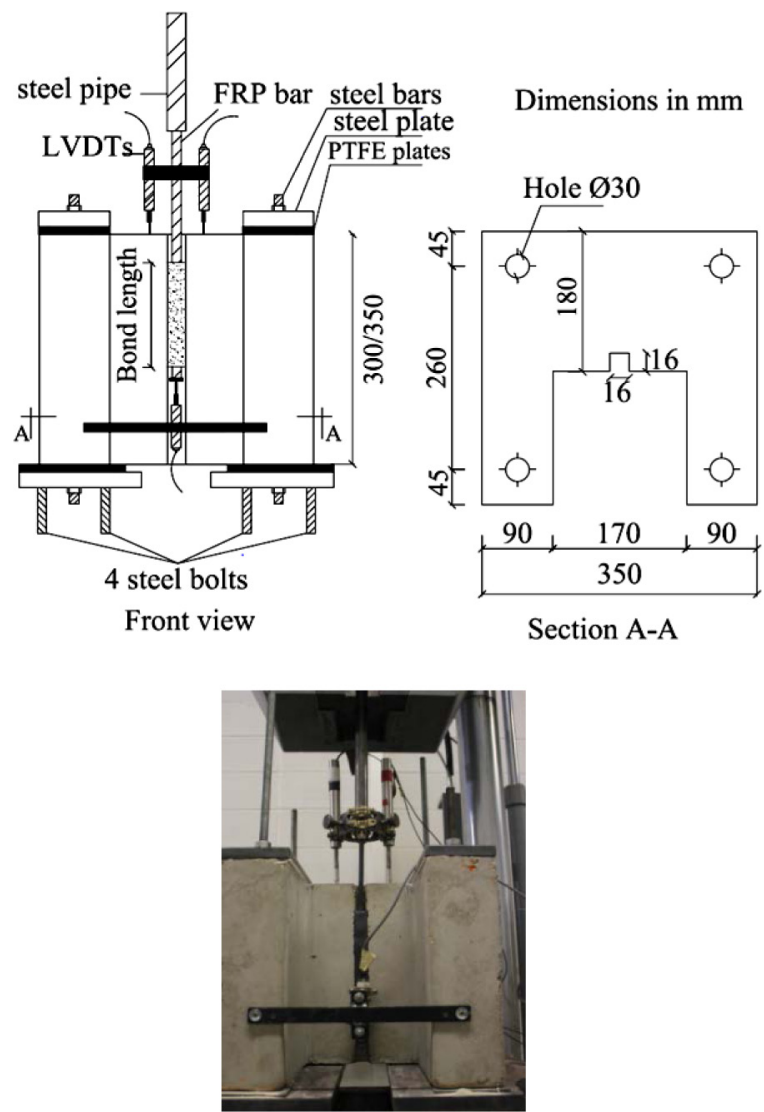

Fig. 1. Test specimen, test setup and instrumentation 
tal tests (according to the ACI 440.3R-04 2004) were 170 and $64 \mathrm{GPa}$ for $E_{f}$ with a corresponding $f_{f u}$ equals 2350 and 1350 for CFRP and GFRP bars respectively. The surface treatment of the FRP bars is shown in Figure 2.

The NSM bars were installed into the grooves using three types of epoxy resins (A, B and D). The first resin (A) MBrace ADHESIVE HT (BASF) consisted of primer painted to the groove surfaces before introducing the main epoxy paste. The second resin (B) was POLYFIXER EP (ROBERLO). The third resin (D) was obtained by adding a special additive to the second resin (Polypropylene glycol diglycidyl ether, Grilonit ${ }^{\circledR}$ F 704 at $3.76 \%$ of weight) in order to obtain different mechanical properties. The properties of the adhesives obtained from experimental tests performed according to the recommendations of ISO-5271 (1993) and UNE-EN13412 (2008) were 5761, 8000 and $6900 \mathrm{MPa}$ for the modulus of elasticity with a corresponding compressive strength equal to $70.2,95.5$ and $84.8 \mathrm{MPa}$, while the tensile strength was 28.9, 23 and $21 \mathrm{MPa}$ for the three types of epoxy A, B and D respectively.

\subsection{Test set up, instrumentation and test variables}

The specimens were tested using the modified pull-out test set up shown in Figure 1. Four steel bars were used to attach the specimens to the testing machine. The load was applied to the NSM bar under a displacement controlled rate of $0.003 \mathrm{~mm} / \mathrm{s}$ up to failure. The loaded end slip as well as the free end slip was measured using displacement transducers (LVDTs) as shown in Figure 1. Adhesive type (A, B, D), FRP material ( $\mathrm{C}=$ carbon, $\mathrm{G}=$ glass $)$ and bond length $(\mathrm{S}=48, \mathrm{M}=96 \mathrm{~mm}, \mathrm{~L}=192 \mathrm{~mm}$, and $\mathrm{T}=240 \mathrm{~mm}$ ) were the main variables in the tests. All specimens had the same groove size $\left(16 \times 16 \mathrm{~mm}^{2}\right)$, and only one size of FRP bar, $8 \mathrm{~mm}$ in diameter, was used. The details of the specimens are showed in Table 1 where the last characters in the specimen name indicate the specimen number $(a, b, c)$.

\section{Results and discussion}

Table 2 shows the test results for specimens with CFRP bars while Table 3 shows the test results for specimens with GFRP bars. In these tables, the type of epoxy, the maximum load of the NSM joint $\left(F_{\max }\right)$, the average value of maximum load for analogous specimens $\left(F_{\text {max }, a v}\right)$, the maximum tensile stress in the FRP bar $\left(f_{f, \max }=\right.$

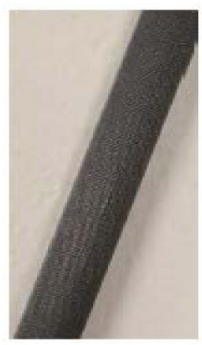

(a) Carbon

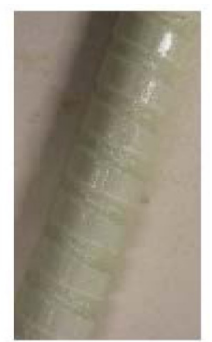

(b) Glass
Fig. 2. Surface treatment of the FRP bars
Table 1. Configuration of tested specimens with CFRP and GFRP bars

\begin{tabular}{|c|c|c|c|}
\hline $\begin{array}{l}\text { Specimen } \\
\text { with CFRP }\end{array}$ & $\begin{array}{c}\text { Specimen } \\
\text { with GFRP }\end{array}$ & $\begin{array}{c}\text { Adhesive } \\
\text { type }\end{array}$ & $\begin{array}{l}\text { Bond } \\
\text { length }\end{array}$ \\
\hline MAC-a & MAG-a & $\mathrm{A}$ & $12 d_{b}$ \\
\hline MAC-b & MAG-b & $\mathrm{A}$ & $12 d_{b}$ \\
\hline LAC-a & LAG-a & $\mathrm{A}$ & $24 d_{b}$ \\
\hline LAC-b & LAG-b & $\mathrm{A}$ & $24 d_{b}$ \\
\hline TAC-a & - & $\mathrm{A}$ & $30 d_{b}$ \\
\hline TAC-b & - & $\mathrm{A}$ & $30 d_{b}$ \\
\hline- & SBG-a & B & $6 d_{b}$ \\
\hline- & SBG-b & B & $6 d_{b}$ \\
\hline MBC-a & MBG-a & B & $12 d_{b}$ \\
\hline MBC-b & MBG-b & B & $12 d_{b}$ \\
\hline LBC-a & LBG-a & B & $24 d_{b}$ \\
\hline LBC-b & LBG-b & B & $24 d_{b}$ \\
\hline- & LBG-c & $\mathrm{B}$ & $24 d_{b}$ \\
\hline TBC-a & TBG-a & B & $30 d_{b}$ \\
\hline TBC-b & TBG-b & B & $30 d_{b}$ \\
\hline- & SDG-a & $\mathrm{D}$ & $6 d_{b}$ \\
\hline- & SDG-b & $\mathrm{D}$ & $30 d_{b}$ \\
\hline MDC-a & MDG-a & $\mathrm{D}$ & $12 d_{b}$ \\
\hline MDC-b & MDG-b & $\mathrm{D}$ & $12 d_{b}$ \\
\hline LDC-a & LDG-a & $\mathrm{D}$ & $24 d_{b}$ \\
\hline LDC-b & LDG-b & $\mathrm{D}$ & $24 d_{b}$ \\
\hline LDC-c & - & $\mathrm{D}$ & $24 d_{b}$ \\
\hline TDC-a & - & $\mathrm{D}$ & $30 d_{b}$ \\
\hline TDC-b & - & $\mathrm{D}$ & $30 d_{b}$ \\
\hline
\end{tabular}

$F_{\text {max }, a v} / A_{f}, A_{f}$ is the cross section area of the FRP bar), the efficiency factor $\left(\eta=f_{f, \text { max }} / f_{f u}\right)$, the average value of the maximum bond stress at the bar epoxy interface $\left(F_{\text {max }}\right.$ av at $\left.F=F_{\text {max }, a v}\right)$ and free end slip $\left(s_{f e}\right)$ are reported. The average bond stress-slip curves for all the tested specimen are also reported and discussed. The average bond stress $\left(F_{a v)}\right.$ and loaded end slip $\left(s_{l e}\right)$ are obtained from:

$$
\begin{gathered}
\tau_{a v}=\frac{F}{\pi d_{b} L_{b}} ; \\
S_{l e}=S_{t}-\frac{F L}{E_{f} A_{f}},
\end{gathered}
$$

where $\tau_{a v}$ is the average bond stress at the bar epoxy interface, $F$ is the applied force, $d_{b}$ is the bar diameter, $L_{b}$ is the bond length, $s_{t}$ is the average measured slip from the top LVDTs, $L$ is the length between the top surface of bonded length and top LVDTs, $E_{f}$ is the modulus of elasticity of the bar, and $A_{f}$ is the crosssectional area. The test results are discussed in detail in the following. 
Table 2. Test results for specimens with CFRP bars

\begin{tabular}{|c|c|c|c|c|c|c|c|c|c|}
\hline Specimen & $\begin{array}{l}\text { Epoxy } \\
\text { type }\end{array}$ & $\begin{array}{c}n \\
\left(L_{\mathrm{b}} / d_{\mathrm{b}}\right)\end{array}$ & $\begin{array}{l}F_{\max } \\
(\mathrm{kN})\end{array}$ & $\begin{array}{c}F_{\max , a v} \\
(\mathrm{kN})\end{array}$ & $\begin{array}{l}f_{f, \max } \\
(\mathrm{MPa})\end{array}$ & $\eta(\%)$ & $\begin{array}{l}F_{\text {max }, a v} \\
(\mathrm{MPa})\end{array}$ & $S_{f e}(\mathrm{~mm})$ & $\begin{array}{l}\text { Failure } \\
\text { mode }\end{array}$ \\
\hline$\overline{\mathrm{MAC}-\mathrm{a}}$ & $\mathrm{A}$ & 12 & 26.89 & & & & & 0.097 & B-E \\
\hline$\overline{\mathrm{MAC}-\mathrm{b}}$ & $\mathrm{A}$ & 12 & 27.77 & 27.33 & 543.8 & 23.1 & 11.32 & 0.028 & B-E \\
\hline LAC-a & $\mathrm{A}$ & 24 & 40.12 & & & & & - & LC, B-E \\
\hline LAC-b & A & 24 & 39.97 & 40.00 & 795.9 & 33.9 & 8.28 & 0.057 & LC, B-E \\
\hline TAC-a & $\mathrm{A}$ & 30 & 48.0 & & & & & 0.044 & $\overline{L C}, \mathrm{~B}-\mathrm{E}$ \\
\hline TAC-b & $\mathrm{A}$ & 30 & 48.70 & 48.35 & 962.0 & 41.0 & 6.41 & 0.030 & LC, B-E \\
\hline MBC-a & B & 12 & 39.32 & & & & & 0.127 & $\mathrm{CC}, \mathrm{B}-\mathrm{E}$ \\
\hline MBC-b & B & 12 & 39.54 & 39.43 & 784.5 & 33.4 & 13.07 & 0.243 & CC, B-E \\
\hline LBC-a & B & 24 & 48.99 & & & & & 0.078 & B-E \\
\hline LBC-b & $\mathrm{B}$ & 24 & 47.31 & 48.15 & 958.0 & 40.8 & 9.98 & 0.195 & B-E \\
\hline TBC-a & B & 30 & 54.79 & & & & & 0.088 & B-E \\
\hline TBC-b & B & 30 & 58.09 & 56.44 & 1123.0 & 47.8 & 9.36 & 0.075 & B-E \\
\hline MDC-a & $\mathrm{D}$ & 12 & 30.12 & & & & & 0.109 & B-E \\
\hline MDC-b & $\mathrm{D}$ & 12 & 27.92 & 29.52 & 587.4 & 25.0 & 12.23 & 0.035 & B-E \\
\hline LDC-a & $\mathrm{D}$ & 24 & 49.92 & & & & & 0.003 & B-E \\
\hline LDC-b & $\mathrm{D}$ & 24 & 44.43 & & & & & 0.118 & B-E \\
\hline LDC-c & $\mathrm{D}$ & 24 & 44.37 & 46.24 & 920.0 & 39.2 & 9.58 & 0.085 & CC, B-E \\
\hline TDC-a & $\mathrm{D}$ & 30 & 53.77 & & & & & 0.001 & $\mathrm{CC}$ \\
\hline TDC-b & $\mathrm{D}$ & 30 & 61.67 & 57.52 & 1144.0 & 48.7 & 9.53 & 0.231 & $\mathrm{CC}$ \\
\hline
\end{tabular}

$\mathrm{B}-\mathrm{E}=$ bar epoxy interface failure; $\mathrm{CC}=$ concrete cracking; $\mathrm{LC}=$ longitudinal cracking of the epoxy.

\subsection{NSM CFRP results}

In this section the load capacity, failure mode and average bond stress of the CFRP bars are discussed. As seen in Table 2, the load capacity of the NSM joint increased as the bond length increased whatever the epoxy type. But the load capacity also increased when the epoxy type changed from $\mathrm{A}$ to $\mathrm{B}$ or from $\mathrm{A}$ to $\mathrm{D}$, although at a different percentage. The predominant failure mode of specimens with NSM CFRP bars was bar-epoxy interface failure (Fig. 3a), except for the two specimens TDC-a and TDC-b that failed due to concrete cracking (Fig. 3b). Longitudinal splitting cracks appeared in the epoxy paste in specimens bonded with epoxy A (Fig. 4a), while concrete tensile cracks appeared on the concrete's surface in specimens bonded with epoxy D (specimens TDC-a and TDC-b, Fig. 4b).

In specimens with CFRP bars bonded with epoxy A, increasing the $L_{b}$ from $12 d_{b}$ to $24 d_{b}$ increased the average load capacity $\left(F_{\max , a v}\right)$ by $46.36 \%$, while increasing $L_{b}$ from $12 d_{b}$ to $30 d_{b}$ increased $F_{\max , a v}$ by $76.91 \%$. In other words, an increase in $L_{b}$ of $25 \%$ (from $24 d_{b}$ to $30 d_{b}$ ) increased $F_{\max , a v}$ by $20.88 \%$.

In specimens with CFRP bars bonded with epoxy B, increasing the $L_{b}$ from $12 d_{b}$ to $24 d_{b}$ increased $F_{\text {max }, a v}$ by $22.11 \%$, while an increase from $12 d_{b}$ to $30 d_{b}$ increased $F_{\text {max }, a v}$ by $43.14 \%$. In other words, increasing the bond length by $25 \%$ increased $F_{\max , a v}$ by $21.03 \%$. Changing the epoxy type from A to B increased the $F_{\max , a v}$ by

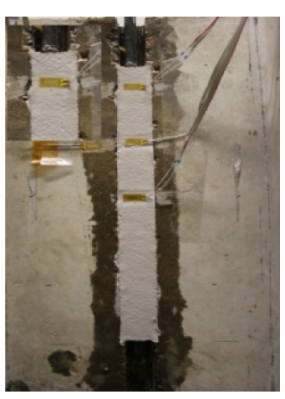

(a) TAC-a

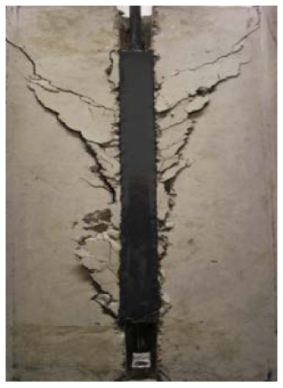

(b) TDC-b
Fig. 3. Failure mode of specimens with CFRP bars

$43.98 \%, 20.38 \%$ and $16.73 \%$ for bond lengths $12 d_{b}, 24 d_{b}$ and $30 d_{b}$ respectively.

To assess the effect of epoxy type on the load capacity, specimens bonded with epoxy D were also tested.

Results for these specimens indicated that increasing $L_{b}$ from $12 d_{b}$ to $24 d_{b}$ increased the $F_{\max , a v}$ by $56.64 \%$, while increasing the $L_{b}$ from $12 d_{b}$ to $30 d_{b}$ increased $F_{\text {max }, a v}$ by $94.85 \%$. In contrast, changing the epoxy type from B to D decreased $F_{\max , a v}$ by $9.91 \%$ and $3.97 \%$ for the bond lengths $12 d_{b}$ and $24 d_{b}$, while it increased $F_{\text {max }, a v}$ by $1.91 \%$ for specimens with bond length $30 d_{b}$.

From these results it is clear that the effect of epoxy type on load capacity was influenced by the bond length (and vice versa). When the difference in mechanical properties between epoxy D and A was $1193 \mathrm{MPa}(+19.8 \%)$, 
Table 3. Test results for specimens with GFRP bars

\begin{tabular}{|c|c|c|c|c|c|c|c|c|c|}
\hline Specimen & $\begin{array}{l}\text { Epoxy } \\
\text { type }\end{array}$ & $\begin{array}{c}n \\
\left(L_{b} / d_{b}\right) \\
\end{array}$ & $\begin{array}{l}F_{\max } \\
(\mathrm{kN})\end{array}$ & $\begin{array}{c}F_{\max , a v} \\
(\mathrm{kN})\end{array}$ & $\begin{array}{l}f_{f, \max } \\
(\mathrm{MPa})\end{array}$ & $\begin{array}{c}\eta \\
(\%)\end{array}$ & $\begin{array}{c}F_{\max , a v} \\
(\mathrm{MPa})\end{array}$ & $\begin{array}{c}S_{f e} \\
(\mathrm{~mm})\end{array}$ & $\begin{array}{l}\text { Failure } \\
\text { mode }\end{array}$ \\
\hline MAG-a & A & 12 & 28.32 & & & & & 0.002 & $\mathrm{LC}, \mathrm{CC}$ \\
\hline MAG-b & A & 12 & 27.86 & 28.09 & 558.9 & 41.4 & 11.64 & 0.685 & $\mathrm{LC}, \mathrm{CC}$ \\
\hline LAG-a & A & 24 & 36.23 & & & & & 0.094 & $\mathrm{LC}, \mathrm{CC}, \mathrm{ES}$ \\
\hline LAG-b & A & 24 & 38.92 & 37.57 & 747.5 & 55.4 & 7.78 & - & $\mathrm{LC}, \mathrm{CC}, \mathrm{ES}$ \\
\hline SBG-a & B & 6 & 18.99 & & & & & 0.265 & $\mathrm{CC}, \mathrm{B}-\mathrm{E}$ \\
\hline SBG-b & B & 6 & 19.51 & 19.25 & 383.0 & 28.3 & 15.95 & 0.751 & $\mathrm{CC}, \mathrm{B}-\mathrm{E}$ \\
\hline MBG-a & B & 12 & 35.31 & & & & & 0.327 & CC, B-E \\
\hline MBG-b & B & 12 & 32.93 & 34.12 & 678.9 & 50.3 & 14.14 & 0.125 & $\mathrm{CC}, \mathrm{CS}$ \\
\hline LBG-a & B & 24 & 56.67 & & & & & 0.258 & $\mathrm{CC}, \mathrm{BD}$ \\
\hline LBG-b & B & 24 & 44.57 & & & & & 0.233 & $\mathrm{CC}, \mathrm{BD}$ \\
\hline LBG-c & B & 24 & 48.06 & 49.76 & 990.1 & 73.3 & 10.31 & 0.371 & $\mathrm{CC}, \mathrm{BD}$ \\
\hline TBG-a & B & 30 & 60.87 & & & & & 0.073 & $\mathrm{CC}, \mathrm{CS}$ \\
\hline TBG-b & B & 30 & 60.15 & 60.51 & 1203.9 & 89.2 & 10.03 & 0.019 & $\mathrm{CC}, \mathrm{CS}$ \\
\hline SDG-a & $\mathrm{D}$ & 6 & 19.83 & & & & & 0.815 & CC, B-E \\
\hline SDG-b & D & 6 & 22.39 & 21.11 & 420.0 & 31.1 & 17.50 & 0.246 & CC, B-E \\
\hline MDG-a & D & 12 & 33.60 & & & & & 0.665 & $\mathrm{CC}, \mathrm{CS}$ \\
\hline MDG-b & $\mathrm{D}$ & 12 & 33.14 & 33.37 & 663.9 & 49.2 & 13.83 & 0.664 & $\mathrm{CC}, \mathrm{B}-\mathrm{E}$ \\
\hline LDG-a & $\mathrm{D}$ & 24 & 52.10 & & & & & 0.298 & $\mathrm{CC}, \mathrm{BD}$ \\
\hline LDG-b & D & 24 & 57.79 & 54.95 & 1093.3 & 81.0 & 11.38 & 0.290 & $\mathrm{BD}$ \\
\hline
\end{tabular}

$\mathrm{CC}=$ concrete cracking; $\mathrm{LC}=$ longitudinal cracking of the epoxy; $\mathrm{B}-\mathrm{E}=$ bar epoxy interface failure;

$\mathrm{ES}=$ epoxy splitting; $\mathrm{CS}=$ concrete splitting and bar damage.

14.6 $\mathrm{MPa}(+20.8)$ and 2.1 $\mathrm{MPa}(+11.1)$ for the modulus of elasticity, compressive strength and tensile strength respectively, specimens bonded with epoxy D had higher load capacities, by approximately $8 \%, 15.6 \%$ and $19.97 \%$ for bond lengths $12 d_{b}, 24 d_{b}$ and $30 d_{b}$ respectively, than those bonded with epoxy A (with the same failure mode). Although the difference in epoxy properties between types $\mathrm{B}$ and $\mathrm{D}$ was $1100 \mathrm{MPa}(+13.8 \%), 10.7 \mathrm{MPa}$ $(+10.7)$ and $2.0 \mathrm{MPa}(+8.7 \%)$ for modulus of elasticity, compressive strength and tensile strength respectively (similar absolute values to those between epoxy D and A), changing the epoxy from B to D caused a slight increase in the load capacities of the NSM bars at bond length $\left(30 d_{b}\right)$, while at other lengths $\left(12 d_{b}\right.$ and $\left.24 d_{b}\right)$ the load experienced a slight reduction. It would seem that the modification in the resin enhanced the bond behaviour with this kind of FRP bar by improving the cohesion and friction between the bar and the epoxy paste, and decreasing the slip for longer bond lengths.

Figures 4-6 allow the effect of $L_{b}$ and epoxy type on the average bond stress $\left(\tau_{a v}\right)$ calculated using Eqn (1) to be compared. In Figure 5 the average bond stress slip curves for specimens bonded with epoxy A is shown. It can be seen that as the bond length increases, the average bond stress decreases due to the non-uniform stress distribution along the bond lengths $12 d_{b}$ and $24 d_{b}$, while there is no effect on the average bond stress when the $L_{b}$ changes from $24 d_{b}$ to $30 d_{b}$ as the failure converts from a bar-epoxy interface failure to concrete cracking. The same findings were also observed in the case of specimens bonded with epoxy B and D. On the other hand, these specimens experienced higher average bond stress than those bonded with epoxy A for all bond lengths (Figs 5 and 6).

\subsection{NSM GFRP results}

The effect of load capacity, failure modes and the average bond stress of specimens with GFRP bars are herein discussed. As seen in Table 3, the load capacity of the

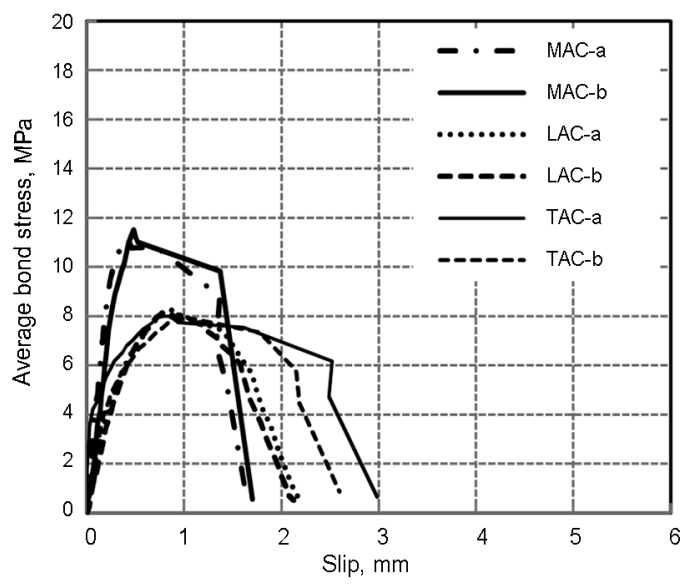

Fig. 4. Average bond stress-slip curves in specimens with CFRP bars bonded with epoxy A 


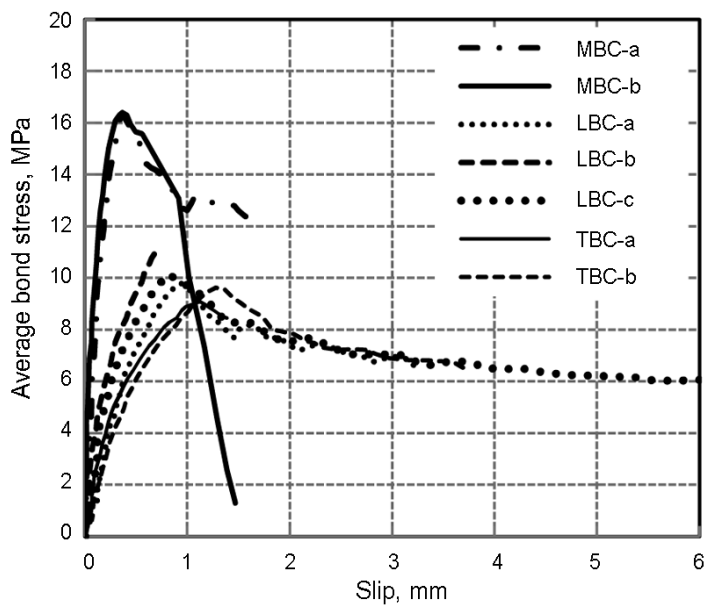

Fig. 5. Average bond stress-slip curves in specimens with CFRP bars bonded with epoxy B

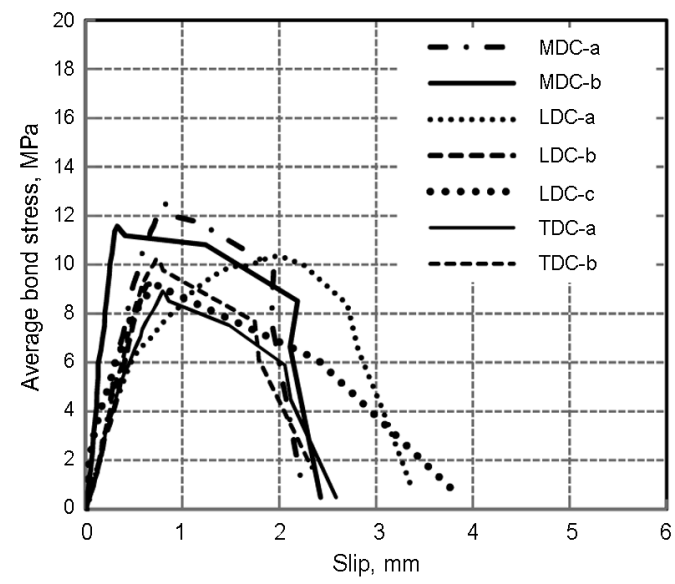

Fig. 6. Average bond stress-slip curves in specimens with CFRP bars bonded with epoxy D

NSM joint increased as the $L_{b}$ increased whatever the epoxy type. Moreover, the load also increased as the epoxy type changed from A to B or from A to D. The failure mode of specimens with GFRP bars depended on the epoxy type.

In specimens with GFRP bars bonded with epoxy A, at the beginning of loading, longitudinal splitting cracks appeared on the epoxy surface. As the load increased, the longitudinal crack propagated until failure. At failure, epoxy splitting caused either the detachment of the surrounding concrete or concrete cracking depended on the bond length (Fig. 7a). For specimens with NSM GFRP bars bonded with epoxy B and D, failures took place with concrete cracking and bar-epoxy interface failure, or bar damage depending mainly on bond length (Figs $7 \mathrm{~b}$ and c).

In specimens with GFRP bars bonded using epoxy A, increasing the $L_{b}$ from $12 d_{b}$ to $24 d_{b}$ increased $F_{\text {max }, a v}$ by $33.75 \%$. Increasing $L_{b}$ from $6 d_{b}$ to $12 d_{b}$ and from $6 d_{b}$ to $24 d_{b}$ increased $F_{\text {max }, a v}$ by $77.25 \%$ and $158.49 \%$ respectively, while increasing it from $12 d_{b}$ to $24 d_{b}$ and from $12 d_{b}$ to $30 d_{b}$ increased $F_{\max , a v}$ by $45.6 \%$ and $77.34 \%$ respectively.

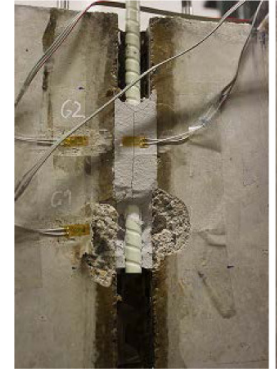

(a) MAG-b

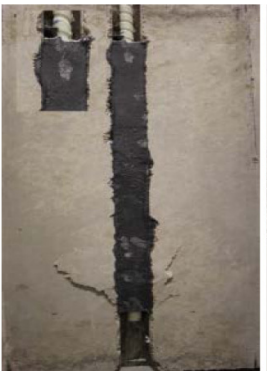

(b) LBG-b

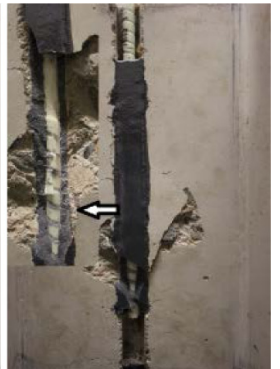

(c) TBG-b
Fig. 7. Failure mode of specimens with GPRP bars

For specimens with NSM bars bonded with epoxy D, increasing $L_{b}$ from $6 d_{b}$ to $12 d_{b}$ and from $6 d_{b}$ to $24 d_{b}$ increased $F_{\max , a v}$ by $58.08 \%$ and $160.3 \%$ respectively, while increasing it from $12 d_{b}$ to $24 d_{b}$ increased $F_{\text {max }, a v}$ by $64.67 \%$. From these results it is clear that as $L_{b}$ increased the percentage of increase in the load capacity was higher in the case of epoxy $\mathrm{B}$ and $\mathrm{D}$ than that of epoxy A, and also that the load increased as $L_{b}$ increased whatever the epoxy type.

Changing the adhesive type from A to B enhanced $F_{\max , a v}$ of the joint by approximately $21.47 \%$ and $32.45 \%$ for bond lengths $12 d_{b}$ and $24 d_{b}$ respectively.

Likewise, changing the adhesive type from A to D enhanced $F_{\text {max }, a v}$ of the joint by approximately $18.8 \%$ and $46.26 \%$ for bond lengths $12 d_{b}$ and $24 d_{b}$ respectively. Using epoxy D enhanced the load capacity of the joint by smaller percentages than when epoxy B was used. Although, as mentioned previously, the difference in epoxy properties between epoxy D and A was nearly equal to that between epoxy B and D, specimens bonded with epoxy D had higher load capacities than those bonded with epoxy A with the dissimilar failure mode. This may have been due to their respective chemical and physical properties, which may have enhanced the cohesion and friction between the bar and the epoxy paste. It seems that in the cases of epoxy B and epoxy D, as the grooved surface of the GFRP bars permitted slips at the bar-epoxy interface, decreasing modules of elasticity of the epoxy paste allowed the bar to deform and then better distribute the bond stress along the bonded length of the bar, without any bar damage in the case of epoxy D.

In this section the effect of $L_{b}$ and epoxy type on $\tau_{a v}$ is explained. Figure 8 shows the average bond stressslip curves for specimens bonded with epoxy A. It can be seen that as $L_{b}$ increases $\tau_{a v}$ decreases as a result of the non-uniform stress distribution lengthwise $L_{b}$. These results assured those reported in Sena-Cruz et al. (2012), Soliman et al. (2011), Sharaky et al. (2013a, 2013b).

The specimens with GFRP bars bonded with epoxy $\mathrm{B}$ and $\mathrm{D}$ experienced higher $\tau_{a v}$ and higher slip than the corresponding specimens bonded with epoxy A (Figs 8-10). This may have been due to damage to the grooved surface of the bar, which increased bar slip. Specimens with NSM GFRP bars, and lower $E_{f}$, experienced 


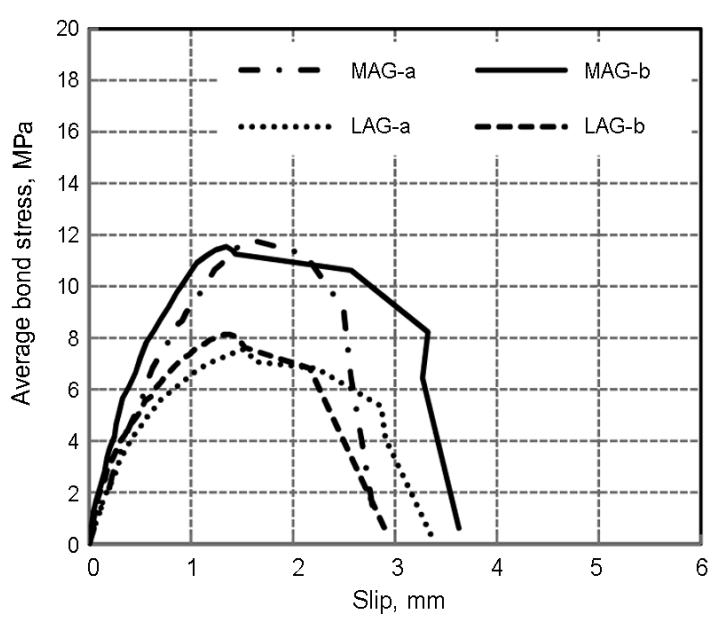

Fig. 8. Average bond stress-slip curves in specimens with GFRP bars bonded with epoxy A

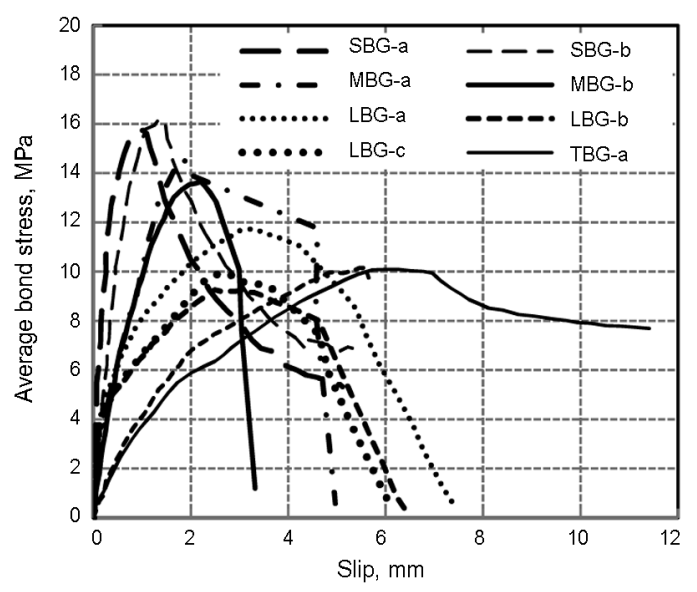

Fig. 9. Average bond stress-slip curves in specimens with GFRP bars bonded with epoxy B

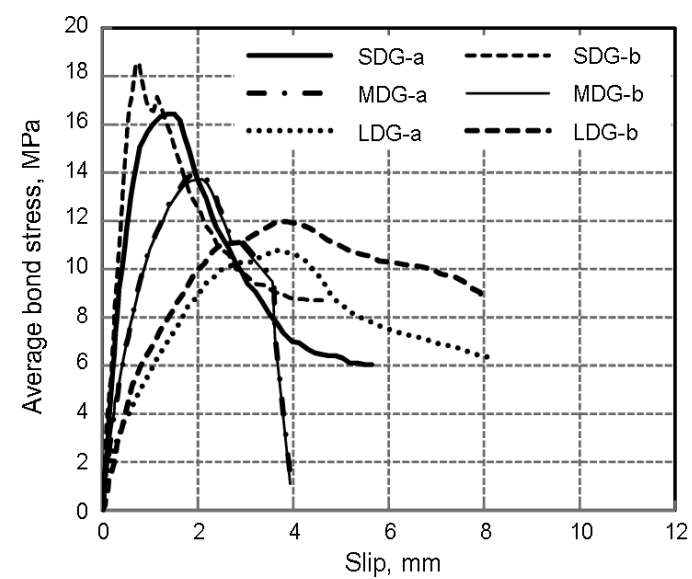

Fig. 10. Average bond stress-slip curves in specimens with GFRP bars bonded with epoxy D

higher slips than those with NSM CFRP bars bonded with the same epoxy type.

\section{Comparison and discussion of results}

The results of this study show the influence of adhesive type on the bond behaviour of NSM FRP reinforcement, something that has also been reported in previous studies (Sharaky et al. 2013b; Novidis et al. 2007; Galati, De Lorenzis 2009). The results indicate that with the same axial stiffness, changing the epoxy type increases the failure load of NSM FRP bars.

Figures 11 and 12 show the effect of epoxy type on $\tau_{\max , a v}$ and the load efficiency $\left(F_{\max } a v\right) / F_{u}$, where $F_{u}$ is the maximum load for FRP bars) respectively of specimens with CFRP bars for three bond lengths: $12 d_{b}, 24 d_{b}$ and $30 d_{b}$. Figure 11 shows how $\tau_{\max a v}$ increased in line with increases in tensile strength and the modulus of elasticity of the epoxy. By contrast, $\tau_{\max a v}$ decreased as the bond length increased, whatever the epoxy type. The percentage decrease in $\tau_{\text {max } a v}$ was insignificant as the $L_{b}$ increased from $24 d_{b}$ to $30 d_{b}$.

On the other hand, the load efficiency of the joint increased as the epoxy properties increased (Fig. 12). The load efficiency also increased as $L_{b}$ increased, whatever the type of epoxy. Specimens with GFRP bars bonded with epoxy D (Figs 13, 14) experienced higher bond stress and load efficiency than the corresponding specimens bonded with epoxy A and B.

Moreover, the load efficiencies were higher than in the corresponding specimens with CFRP bars, as can be seen by comparing Figures 12 and 14 .

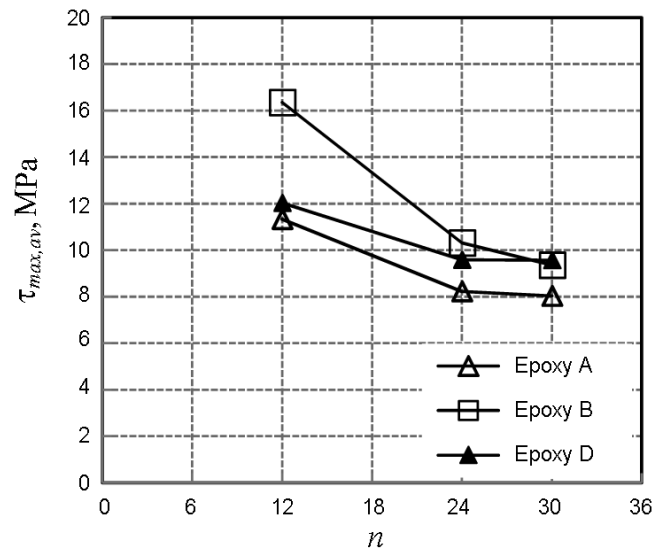

Fig. 11. Effect of epoxy type and bond length for specimens with CFRP bars on $\tau_{\text {max }, a v}\left(n=L_{b} / d_{b}\right)$

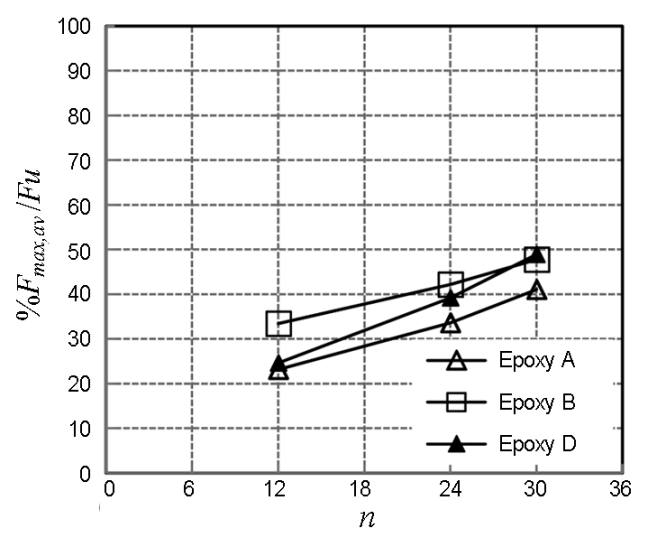

Fig. 12. Effect of epoxy type and bond length for specimens with CFRP bars on $\% F_{\max , a v} / F_{\mathrm{u}} ;\left(n=L_{b} / d_{b}\right)$ 


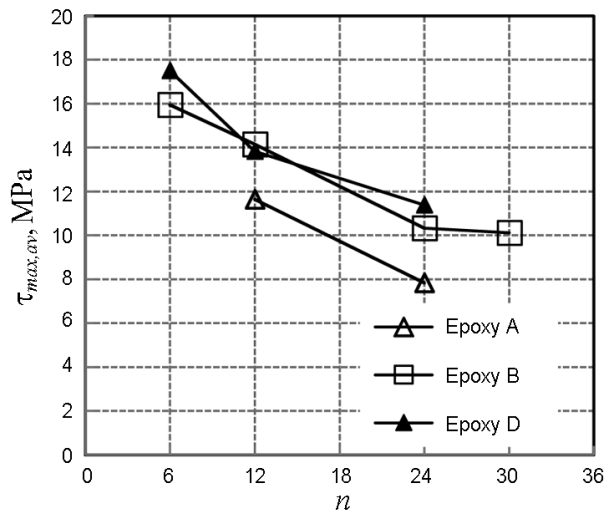

Fig. 13. Effect of epoxy type and bond length for specimens with GFRP bars on $\tau_{\max , a v}\left(n=L_{b} / d_{b}\right)$

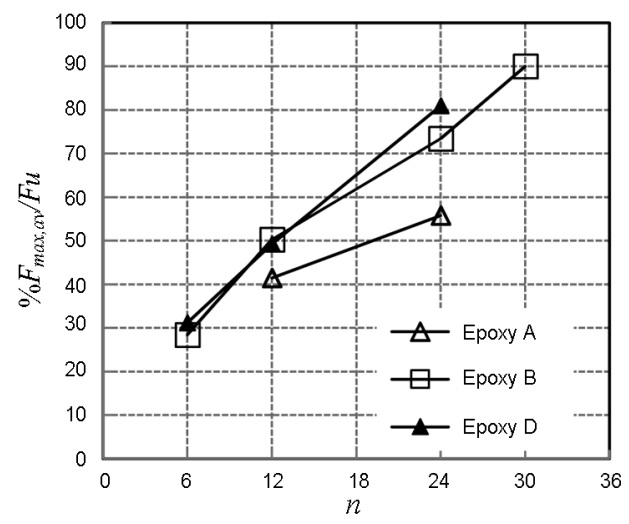

Fig. 14. Effect of epoxy type and bond length for specimens with GFRP bars on $\% F_{\max , a v} / F_{\mathrm{u}} ;\left(n=L_{b} / d_{b}\right)$

\section{Conclusions}

In this paper a modified pull-out test was performed to investigate the effect of the adhesive properties on the bond performance of NSM FRP bars in concrete. Three types of epoxy adhesive (A, B and D) were used to bond the FRP bars to concrete: type A (MBrace ADHESIVE HT); type B (POLYFIXER EP); and type D, obtained by modifying type B. Two types of FRP bars, carbon (C) and glass $(\mathrm{G}), 8 \mathrm{~mm}$ in diameter, were used. Three bond lengths $\left(12 d_{b}, 24 d_{b}, 30 d_{b}\right)$ were used for specimens with CFRP bars while four bond lengths $\left(6 d_{b}, 12 d_{b}, 24 d_{b}\right.$, $30 d_{b}$ ) were used for specimens with GFRP bars. The load capacity, mode of failure and loaded end slip were recorded. From the results it was concluded that:

The adhesive type had a great effect on the behaviour of NSM bars. This effect varied according to the bond length and FRP properties.

The predominant failure mode of specimens with CFRP bars was bar-epoxy interface failure, except in the cases of the two specimens TDC-a and TDC-b, which failed by concrete cracking. On the other hand, the predominant failure mode of specimens with GFRP bars depended on the epoxy type. For specimens with GFRP bars bonded with epoxy A, longitudinal splitting cracks looked on the epoxy surface for relatively low loads; these progressed until failure, producing detachment of the surrounding concrete or concrete cracking, depending on the bond length. For specimens with GFRP bars bonded with epoxy B and D, failures took place with concrete cracking, bar-epoxy interface failure, or bar damage, depending mainly on bond length and epoxy type.

In specimens with CFRP bars, changing the adhesive type from A to B enhanced $F_{\max , a v}$ of the joint by approximately $44.27 \%, 20.38 \%$ and $16.73 \%$ for bond lengths $12 d_{b}, 24 d_{b}$ and $30 d_{b}$ respectively. Furthermore, changing the adhesive type from A to D enhanced $F_{\max , a v}$ of the joint by approximately $8 \%, 15.6 \%$ and $19.97 \%$ for bond lengths $12 d_{b}, 24 d_{b}$ and $30 d_{b}$ respectively. Although the differences in properties between epoxy $\mathrm{B}$ and $\mathrm{D}$ were nearly the same as between epoxy A and D, changing the epoxy from $\mathrm{B}$ to D resulted in a slight increase $F_{\max , a v}$ of the NSM bars at bond length $30 d_{b}$, and a decrease at other lengths $\left(12 d_{b}\right.$ and $24 d_{b}$ ). It seems that this change in epoxy type alters the bond behaviour with this kind of FRP bar by enhancing the cohesion and friction between the bar and epoxy paste and decreasing the slip at greater bond lengths.

For specimens with GFRP bars, changing the adhesive type from A to B enhanced $F_{\max , a v}$ of the joint by approximately $21.47 \%$ and $32.45 \%$ for bond lengths $12 d_{b}$ and $24 d_{b}$ respectively; changing the adhesive type from A to D enhanced $F_{\max , a v}$ of the joint by approximately $18.8 \%$ and $46.26 \%$ for bond length $12 d_{b}$ and $24 d_{b}$ respectively. Although the difference in properties between epoxy $\mathrm{D}$ and $\mathrm{A}$ was nearly the same as between epoxy B and D, specimens bonded with epoxy D had a higher load capacity than those bonded with epoxy A, although with a dissimilar failure mode epoxy D slightly enhanced $F_{\max , a v}$ of the joint with respect to specimens bonded with epoxy B. It seems that with this latter kind of epoxy, as the grooved surface of the GFRP bars permitted slips at the bar-epoxy interface, decreasing modules of elasticity (as a result of adding additive to obtain epoxy D) allowed better distribution of the bond stress along the bonded length of the bar, without bar damage in the case of epoxy D.

Bond length had a great effect on the bond behaviour of NSM joints; increasing it raised $F_{\max , a v}$ and lowered $\tau_{a v}$ of NSM FRP bars whatever the epoxy type. An increase of from $12 d_{b}$ to $30 d_{b}$ for specimens with bars bonded with epoxy A, B and D enhanced $F_{\max , a v}$ by approximately $76.91 \%, 43.14 \%$ and $94.85 \%$ respectively, while an increase from $12 d_{b}$ to $24 d_{b}$ enhanced $F_{\text {max }, a v}$ by approximately $33.75 \%, 45.84 \%$ and $64.67 \%$ respectively.

With the same FRP axial stiffness, the load capacity of NSM FRP bars was dependent on the epoxy type and bond length. This suggests a link between the influence of these two factors, and a need for further experimental and numerical work. 


\section{Acknowledgements}

The authors acknowledge the support provided by the Spanish Government (Ministerio de Ciencia e Innovación), Project ref. BIA2010-20234-C03-02. The first author also acknowledges support from the Generalitat de Catalunya for an FI predoctoral grant, ref. 2011FI_B 00003.

\section{References}

ACI 440.3R-04. 2004. Guide test methods for fiber-reinforced polymers (FRPS) for reinforcing or strengthening concrete structures. Farmington Hills, Michigan, USA. 2004. $40 \mathrm{p}$.

ACI 440.2R-08. 2008. Guide for the design and construction of externally bonded FRP systems for strengthening concrete structures. Reported by ACI Committee 440, American Concrete Institute, 2008. 80 p.

Al Mahmoud, F.; Castel, A.; François, R.; Tourneur, C. 2009. Strengthening of RC members with near-surface mounted CFRP rods, Composite Structures 91(2): 138-147. http://dx.doi.org/10.1016/j.compstruct.2009.04.040

Al Mahmoud, F.; Castel, A.; François, R.; Tourneur, C. 2010. RC beams strengthened with NSM CFRP rods and modelling of peeling-off failure, Composite Structures 92(8): 19201930. http://dx.doi.org/10.1016/j.compstruct.2010.01.002

Al Mahmoud, F.; Castel, A.; François, R. 2012. Failure modes and failure mechanisms of RC members strengthened by NSM CFRP composites - analysis of pull-out failure mode, Composites Part B: Engineering 43(4): 1893-1901. http://dx.doi.org/10.1016/j.compositesb.2012.01.020

Barros, J. A. O.; Fortes, A. S. 2005. Flexural strengthening of concrete beams with CFRP laminates bonded into slits, Cement and Concrete Composites 27(4): 471-480. http://dx.doi.org/10.1016/j.cemconcomp.2004.07.004

Barros, J. A. O.; Dias, S. J. E.; Lima, J. L. T. 2007. Efficacy of CFRP-based techniques for the flexural and shear strengthening of concrete beams, Cement and Concrete Composites 29(3): 203-217. http://dx.doi.org/10.1016/j.cemconcomp.2006.09.001

Barros, J. A. O.; Costa, I. G.; Ventura-Gouveia, A. 2011. CFRP flexural and shear strengthening technique for RC beams: experimental and numerical research, Advances in Structural Engineering 14(3): 551-571. http://dx.doi.org/10.1260/1369-4332.14.3.551

Bilotta, A.; Ceroni, F.; Di Ludovico, M.; Nigro, E.; Pecce, M.; Manfredi, G. 2011. Bond efficiency of EBR and NSM FRP systems for strengthening concrete members, Journal of Composites for Construction 15(5): 757-772. http://dx.doi.org/10.1061/(ASCE)CC.1943-5614.0000204

Bulavs, F.; Radinsh, I.; Tirans, N. 2005. Improvement of capacity in bending by the use of FRP layers on RC beams, Journal of Civil Engineering and Management 9(3): 169174. http://dx.doi.org/10.1080/13923730.2005.9636347

Costa, I.; Barros, J. 2010. Flexural and shear strengthening of $\mathrm{RC}$ beams with composite materials - the influence of cutting steel stirrups to install CFRP strips, Cement and Concrete Composites 32(7): 544-553.

http://dx.doi.org/10.1016/j.cemconcomp.2010.03.003

De Lorenzis, L.; Rizzo, A.; La Tegola, A. 2002. A modified pull-out test for bond of near-surface mounted FRP rods in concrete, Composites Part B: Engineering 33(8): 589-603.

http://dx.doi.org/10.1016/S1359-8368(02)00052-5
De Lorenzis, L.; Teng, J. G. 2007. Near-surface mounted FRP reinforcement: an emerging technique for strengthening structures, Composites: Part B 38 (2007): 119-143. http://dx.doi.org/10.1016/j.compositesb.2006.08.003

Dias, S.; Barros, J. 2010. Performance of reinforced concrete T-beams strengthened in shear with NSM CFRP laminates, Engineering Structures 32(2): 373-384. http://dx.doi.org/10.1016/j.engstruct.2009.10.001

El-Hacha, R.; Rizkalla, S. 2004. Near-surface-mounted fiber-reinforced polymer reinforcements for flexural strengthening of concrete structures, ACI Structural Journal 101(5): 717-726.

Galati, D.; De Lorenzis, L. 2009. Effect of construction details on the bond performance of NSM FRP bars in concrete, Advances in Structural Engineering 12: 683-700. http://dx.doi.org/10.1260/136943309789867836

Hassan, T.; Rizkalla, S. 2003. Investigation of bond in concrete structures strengthened with near surface mounted carbon fiber reinforced polymer strips, Journal of Composites for Construction 7(3): 248-257.

http://dx.doi.org/10.1061/(ASCE)1090-0268(2003)7:3(248)

Hassan, T.; Rizkalla, S. 2004. Bond mechanism of near-surface-mounted fiber-reinforced polymer bars for flexural strengthening of concrete structures, ACI Structural Journal 101(6): 830-839.

Hajsadeghi, M.; Alaee, F. J.; Shahmohammadi, A. 2011. Investigation on behaviour of square/rectangular reinforced concrete columns retrofitted with FRP Jacket, Journal of Civil Engineering and Management 17(3): 400-408. http://dx.doi.org/10.3846/13923730.2011.594155

ISO 527-1:1993. Plastics - determination of tensile properties - Part 1: general principles. International Organization for Standardization, 1993.

Novidis, D.; Pantazopoulou, S.; Tentolouris, E. 2007. Experimental study of bond of NSM FRP reinforcement, Construction and Building Materials 21(8): 1760-1770. http://dx.doi.org/10.1016/j.conbuildmat.2006.05.054

Sena-Cruz, J.; Branco, J.; Jorge, M.; Barros, J. A. O.; Silva, C.; Cunha, V. 2012. Bond behaviour between Glulam and GFRP's by pullout tests, Composites: Part B: Engineering 43(3): 1045-1055.

http://dx.doi.org/10.1016/j.compositesb.2011.10.022

Sharaky, I. A.; Torres, L.; Baena, M.; Vilanova, I. 2013a. Effect of different material and construction details on the bond behaviour of NSM FRP bars in concrete, Construction and Building Materials 38: 890-902. http://dx.doi.org/10.1016/j.conbuildmat.2012.09.015

Sharaky, I. A.; Torres, L.; Baena, M.; Miàs, C. 2013b. An experimental study of different factors affecting the bond of NSM FRP bars in concrete, Composite Structures 99: $350-365$.

http://dx.doi.org/10.1016/j.compstruct.2012.12.014

Soliman, S.; El Salakawy, E.; Benmokrane, B. 2010. Flexural behaviour of concrete beams strengthened with near surface mounted fibre reinforced polymer bars, Canadian Journal of Civil Engineering 37(10): 1371-1382. http://dx.doi.org/10.1139/L10-077

Soliman, S.; El Salakawy, E.; Benmokrane, B. 2011. Bond performance of near-surface mounted FRP bars, Journal of Composites for Construction 15(1): 103-111. http://dx.doi.org/10.1061/(ASCE)CC.1943-5614.0000150

UNE-EN 13412:2008. Products and systems for the protection and repair of concrete structures - test methods determination of modulus of elasticity in compression. AENOR, 2008. 14 p. 
Lluís TORRES. He is a Professor of Structural Engineering and member of the research group on Advanced Materials and Analysis for Structural Design in the Polytechnic School at the University of Girona, Spain. He is member of the fib Task Groups 9.3 "FRP reinforcement for concrete structures" and 4.1 "Serviceability models". His research interests include the experimental and numerical analysis of reinforced concrete structural elements.

Ibrahim Attia SHARAKY. He is an Assistant Lecturer in the Department of Materials Engineering at the University of Zagazig, Egypt, $\mathrm{PhD}$ student in the Department of Mechanical Engineering and Industrial Construction at the University of Girona, and member of the research group on Advanced Materials and Analysis for Structural Design. His research interests include the bond behaviour of NSM FRP reinforcement in concrete and the flexural performance of reinforced concrete elements strengthened with NSM FRP reinforcement.

Cristina BARRIS. She is a Lecturer in the Department Girona, Department of Mechanical Engineering and Industrial Construction at the University of Girona, and member of the research group on Advanced Materials and Analysis for Structural Design. Her research interests include the experimental and numerical behaviour of FRP reinforced concrete structures.

Marta BAENA. She is a Lecturer in the Department of Mechanical Engineering and Industrial Construction at the University of Girona, and member of the research group on Advanced Materials and Analysis for Structural Design. Her research interests include the bond behaviour of FRP reinforced concrete structures. 